\title{
PENGARUH FAKTOR-FAKTOR KEPUASAN KONSUMEN TERHADAP LOYALITAS KONSUMEN IKLAN DI GADJAH MADA ENTERPRISE
}

\author{
1 Ana Fitriyatul Bilgies \\ Universitas Islam Darul 'Ulum Lamongan \\ anafitriyatulbilgies@unisda.ac.id \\ 2 Arifah Sundari \\ Universitas Islam Darul 'Ulum Lamongan \\ ariefah.sundari@unisda.ac.id \\ 3 Nurul Fauziyah \\ Universitas Islam Darul 'Ulum Lamongan \\ nurul_fauziyah@unisda.ac.id
}

\begin{abstract}
This research is one of the methods used by researchers to determine the level of customer satisfaction that has customer loyalty with various marketing methods that are carried out to provide the number of components that influence consumer loyalty attitudes. In this study also makes the four variables represent some expanded customer satisfaction: Intensifly, and Cross selling. Results of this research,obtained that the cross selling variable provides the biggest contribution to consumer loyalty.
\end{abstract}

Keywords: Consumer Satisfaction, Consumer Loyalty, cross selling.

\begin{abstract}
ABSTRAK
Penelitian ini adalah salah satu cara yang digunakan peneliti untuk mengetahui sebagaimana tingkat dari kepuasan Konsumen yang mempunyai pengaruh yangdengan loyalitas Konsumen dari beberapa metode pemasaran yang di lakukan untuk memberikan jumlah komponen yang mempengaruhi sikap loyalitas pada konsumen. Dalam penelitian ini juga membuat empat variabel dalam mewakili beberapa keppuasan Konsumen yang meliputi : Intensifly, dan Cross selling. Dari hasil perhitungan diketahui bahwa cross selling memberikan kontribusi terbesar terhadap loyalitas Konsumen.
\end{abstract}

Kata kunci : Kepuasan Konsumen, Loyalitas Konsumen, cross selling.

\section{PENDAHULUAN}

Di negara berkembang seperti Indonesia keturuhan mulai beralih dari prioritas kebutuhan primer menjadi kebutuhan skunder. Di Indonesia Kebutuhan terhadap berbagai informasi sangat mudah di akses terutama berkaitan dengan infirmasi produk. Beberapa cara yang digunakan adalah dengan menggunakan media Televisi, radio, 
internet dan juga surat kabar. Pemenuhan kebutuhan atas diri sendiri dan juga akan menjadikan masalah di dalam kehidupan sehari hari. Dimulai dengan kebutuhan primer dan skunder berikut tersier sangat penting di berbagai Negara manapun.

Dari sumber infrormasi tersebut mempunyai beberapa karakteristik yang tidak sama, akan tetapi terdapat kesamaan yaitu diantaranya media tersebut menyampaikan informasi dan juga sebagai alat dalam melakukan komunikasi dengan konsumen dalam bentuk sebuah iklan produk maupun jasa.Dalam memperoleh beberapa informasi yang telah di publikasikan maka yang dibutuhkan untuk melakukan penyampaian adalah Website. Media yang sering dipakai adalah facebook, instagram, twitter dll.

Beberapa media tersebut adalah sebagai sarana untuk memberikan suatu informasi yang dibutuhkan oleh masyarakat. Baik terkait informasi dari dalam maupun luar negeri, baik ekonomi social dan budaya. Dalam melakukan sebuah publikasi untuk pembaca diharapkan baik dari segi isi mampu menyampaikan isi yang akurat, hangat dan terpercaya terkait dengan hal tersebut juga ada beberapa iklan di dalamnya. Penentuan dalam pemasangan iklan disini dibedakan dalam iklan umum (display) dan flash commercial. Dalam meningkatkan pelayanan kepada pemasang iklan dalam website Gadjah Mada, sejak pembuatannya membuka pelayanan melalui kontak yang tertera dalam halaman web, maka hal ini memberikan peluang untuk mengembangkan bisnis dalam penyedia iklan produk komersil sebagai tempat untuk menyampaikan informasi produk yang di tawarkan pada konsumen dengan cakupan wilayah meliputi Gadjah Mada Enterprise sebagai coordinator penyedia layanan.

Namun sejak pertengahan 2016 peranan Gadjah Mada Corp dikurangi. Sejak itu pula focus Periklanan di usung oleh bidang unit bisnis dari Gadjah Mada Enterprise, sehingga Memunculkan beberapa website-website serupa yang lainya dan memunculkan sebuah persaingan antar Web dalam memberikan pelayanan kepada pemasang Multimedia. Gadjah Mada Enterprise Kemudian Disebut GM Enterprise menerima order iklan dengan melalui berbagai sumber, yaitu: melalui pemasang iklan secara langsung, melalui layanan dengan telepon, melalui sales marketing dan juga social media.

Dalam penelitian kami ini beberapa pesanan iklan yang diterima GM Enterprise tidak membedakan sumbernya baik dalam melayani proyek iklan layanan masyarakat maupun komersil. Sebagai obyek penelitiannya adalah Konsumen iklan website yang di 
laksanakan oleh GM Enterprise. Dengan Slogan "Murah Tapi Gak Murahan" ternyata bisa menarik minat pemasang iklan dalam halaman Website. Yang awalnya penilitian ini dilakukan dengan 25 responden yang ber posisi sebagai konsumen, sehingga dapat diketahui tiga hal:

Pertama, Pendapat mengenai slogan "Murah Tapi Gak Murahan", 72\% Responden menyatakan bahwa slogan yang di tulisakan memang sesuai kenyataan, $12 \%$ Responden menyatakan belum pasti dan 16\% Responden mengatakan bahwa hal tersebut tidak sesuai.

Kedua, Kepuasan Responden dalam melakukan pemilihan media promosi GM Enterprise sebagai ajang sarana dalam memasang iklan dalam websitenya adalah, yang mana $100 \%$ menyatakan bahwa pelayanannya yang di berikan web builder memuaskan, responsif dan tepat waktu, 90\% Responden menyatakan bahwa dalam melakukan servis pelayanan humble dan sopan dalam menerima semua keluhan responden apabila terjadi masalah dalam pengiklanan produk barang dan jasa dalam website nya.

Ketiga, Loyalitas Konsumen kepada GM Enterprise cukup bagus, hal ini digambarkan dengan $83 \%$ responden memberikan tanggapan dalam melakukan pembayan ulang atas jasa iklan yang di tawarkan. Dengan menggunakan GM Enterprise mereka tidak merasa di rugikan dan $71 \%$ responden melakukan rekomendasi kepada pihak lain untuk menggunakan jasa website builder yang dibuat oleh GM Enterprise dalam memasang iklan promosi produk barang dan jasa mereka. Yang melatar belakangi penelitian tersebut bahwa peneliti memfokuskan pada topik apakah faktorfaktor Intensifly (Keseringan), Cross selling (Proses Pemasaran), mempunyai pengaruh yang penting terhadap loyalitas terhadap Konsumen

\section{TINJAUAN PUSTAKA}

\section{Konsep Jasa}

Menurut Kotler dalam Lupiyoadi (2014:7) "Jasa adalah setiap tindakan atau kegiatan yang dapat ditawarkan oleh satu pihak kepada pihak lain, pada dasarnya tidak berwujud dan tidak mengakibatkan perpindahan kepemilikan apapun. Produksi jasa mungkin berkaitan dengan produk fisik atau tidak." Selanjutnya, (Zethaml dan Bitner : 1996) dalam Lupioyadi (2014:7) memberikan batasan tentang jasa sebagai berikut "Service is all economic activities whose output is not a physical product or 
construction is generally consumed at that time it is produced, and provides added value in forms (such as convenience, amusement, comfort or health). “

Beberapa pengertian tersebut memberikan kesimpulan bahwa Jasa adalah kegiatan ekonomi dengan hasil keluaran yang tidak berwujud yang ditawarkan dari penyedia jasa yaitu perusahaan kepada pengguna jasa atau konsumen. Atas definisi yang di simpulkan diatas, dapat di definisikan bahwa suatu kegiatan konsumsi yang didalamnya memiliki beberapa unsur ketakberwuju atau ketidak bendaan sehingga dapat bermanfaat oleh suatu salah satu fihak dengan fihak yang lainya untuk menciptakan sebuah keterkaitan antara masing masing fihak. Setiap pencipta dari jasa tersebut harus mengetahui serta mengantisipasi atas semua konsewensi dan juga harus memenuhi yang dimaksud dengan kebutuhan atas keinginan Konsumen untuk dijadikan sebagai karkteristik dari sebuah jasa.

\section{Karakteristik Jasa}

Kotler \& Armstrong (Philip Kotler and Gary Amstrong, 1996) mengemukakan bahwa terdapat 4 karakteristik jasa antara lain:

a. Intangibility (Tidak terwujud)

Jasa tidak dengan barang. Jasa bersifat intangible, artinya tidak dapat dilihat, dirasa, diraba, dicium, atau didengar sebelum dibeli. Konsep intangible ini sendiri memiliki dua pengertian yaitu:

- Sesuatu yang tidak dapat disentuh dan tidak dapat dirasa.

- Sesuatu yang tidak mudah didefinisikan, diformulasikan, atau dipahami secara rohaniah.

b. Inseparability (Tidak dipisahkan)

Jasa tidak mengenal persediaan atau penyimpanan dari produk yang telah dihasilkan. Karakteristik ini disebut juga inseparability (tidak dapat dipisahkan) mengingat pada umumnya jasa dihasilkan dan dikonsumsi secara bersamaan. Dalam hubungan penyedia jasa dan pelanggan ini,effektivitas individu yang menyampaikan jasa merupakan unsur penting..

c. Variability (Keanekarupaan)

Jasa bersifat sangat variabel karena merupakan nonstandardized out-put, artinya banyak variasi bentuk, kualitas dan jenis, tergantung pada siapa, kapan, dan 
dimana jasa tersebut dihasilkan.

d. Perishability (Tidak dapat tahan lama)

Jasa tidak dapat tahan lama, karenanya tidak dapat disimpan untuk penggunaan atau penjualan di kemudian hari. Sifat jasa yang tidak tahan lama ini bukanlah masalah kalau permintaan tetap/teratur, karena jasa-jasa sebelumnya dapat dengan mudah disusun terlebih dahulu, kalau permintaan berfluktuiasi, perusahaan jasa akan dihadapkan pada berbagai masalah yang sulit.

\section{Kepuasan Konsumen}

Produk jasa berkualitas mempunyai peranan penting untuk membentuk kepuasan KonsumenBeberapa harapan yang ditimbulkan dan terbentuk oleh pengalaman atas pembelian barang dan jasa terdahulu, berdasarkan kesaksian orang lain dan beberapa janji garansi yang di berikan perusahaan untuk konsumen. Harapan-harapan Konsumen ini akan terus berkembang dengan bertambahnya beberapa kompetitior dan pengalaman yang dimiliki oleh konsumen. Hal ini dapat dipastikan bahwa kepuasan Konsumen, pada umumnya adalah sebuah harapan yang merupakan dasar dari perkiraan atau khayalan dari masing masing konsumen terhadap barang dan jasa yang mereka konsumsi. Hal ini dapat disimpulkan bahwa, adanya harapan besar yang di ungkapkan oleh seorang konsumen untuk melakukan kegiatan bisnis yang berbeda shingga mampu menciptakan presepsi kepuasan yang berbeda dari masing masing konsumen. Menurut Lupiyoadi (2014,7-8) kepuasan atau ketidakpuasan atas konsumen merupakan hasil dari olah emosional konsumen terhadap ketidak sesuaian atas emosional diri dan pendapat individual.

Ketidaksesuaian (discinfirmation) adalah hasil dari perasaan dari sebuah harapan dari setiap konsumen dan kinerja produk yang di manipulasi untuk bias bersaing dengan persaingan yang semakin ketat, semakin banyak produsen atas barang dan jasa tersebut maka pemenuhan atas kebutuhan dan keinginan dari konsumen mampu menyebabkan setiap perusahaan untuk bisa menempatkan prioritas atas tingkat kepuasan konsumen sebagai tujuan pokok dalam suatu perusahaan. Dengan beberapa tanggapan yang diberikan konsumen utnuk perusahaan maka perusahaan harus memperbaiki dan meciptakan sebuah layanan yang mampu memuaskan daya beli masyarakat pada umumnya. Perusahaan diharapkan mampu mengidentifikasi tingkat kepuasan 
konsumennya dengan melakukan umpan balik atas apa yang diberikan perusahaan kepada konsumen tersebut sehingga mampu meningkatkan beberapa pengembangan dan melakukan sebuah implementasi strategis dalam meningkatkan kepuasan konsumen. Hal ini dapat diketahui ketika sebuah peluang tercipta dari sebuah perusahaan untuk dapat mengetahui progress dari perusahaan tersebut.

Pelanggan yang sangat puas akan menyebarkan cerita positif dari mulut ke mulut dan malah akan menjadi iklan berjalan dan berbicara bagi suatu perusahaan, yang akan menurunkan biaya untuk menarik pelanggan baru seperti yang terlihat pada gambar di bawah ini mengenai manfaat darikepuasan pelanggan. Lovelock (Christopher. H Lovelock dan Wright, 2005) mengemukakan bahwa kepuasan pelanggan memberikan banyak manfaat bagi perusahaan, dan tingkat kepuasan pelanggan yang lebih besar. Dalam jangka panjang, akan lebih menguntungkan mempertahankan pelanggan yang baik daripada terus menerus menarik dan membina pelanggan baru untuk menggantikan pelanggan yang pergi.

Faktor-faktor yang yang berpengaruh dalam pelayanan:

- Jaminan: Jaminan yang di berikan oleh penjual dalam model pengembalian harga pembelian atau perbaikan terhadap produk yang telah di reject.

- Respon dan cara memecahkan masalah: Respon yang diungkapkan oleh karyawan dalam mengatasi keluhan yang dihadapi oleh Konsumen.

Faktor-faktor yang yang berpengaruh dengan pembelian:

- Penanganan Konsumen : Hubungan yang terjadi antar konsumen dengan GM Enterprise khususnya dalam melakukan sebuah komunikasi (konsultasi) dengan pengiklanan.

- Kemudahan dan kenyamanan: Convenience of acquisition merupakan beberapa konsep kemudahan serta kenyamanan yang di dapatkan konsumen dari perusahaan terhadap produk yang di tawarkan oleh perusahaan.

\section{Teknik Pengukuran Kepuasan Konsumen}

Metode pengukuran adalah metode yang paling banyak digunakan dalam pengukuran kepuasan Konsumen. Metode ini adalah mengukur kepuasan Konsumen dengan menggunakan beberapa metode pengukuran dengan ciri-ciri sebagai berikut:

1. Pengukuran dapat dilakukan secara langsung seperti dengan pertanyaan 
“Ungkapkan seberapa puas saudara terhadap pelayanan GM Enterprise pada skala berikut: sangat tidak puas, tidak puas, netral, puas, sangat puas" (directly reparted satisfaction).

2. Responden diberi pertanyaan mengenai seberapa besar yang mereka rasakan dalam atribut tersebut (derived dissatisfaction).

3. Responden dapat diminta untuk mengurutkan dari berbagai elemen (atribut) dari penawaran berdasarkan derajat pertanyaan setiap elemen dan seberapa baik kinerja perusahaan dalam masing-masing elemen (importance/performance ratings).

4. Responden diminta untuk menulis ungkapan masalah-masalah yang mereka hadapi berkaitan dengan penawaran dari perusahaan. Disamping itu responden juga diminta untuk menuliskan solusi yang mereka sarankan (problem analysis).

Rumusan kepuasan konsumen menurut Wilton dan Tse, sebagai berikut:

Kepuasan Konsumen $=\mathrm{f}($ expectations, perceived performance $)$

Dari persamaan tersebut dapat diketahui bahwa ada dua variable utama yang menentukan kepuasan konsumen, yaitu Expectation dan perceived performance apabila performance melebihi expectations, maka konsumen akan puas, tetapi apabila sebaliknya maka konsumen akan merasa tidak puas. Oleh karena kepuasan akan menimbulkan loyalitas konsumen, maka loyalitas sebagai variable endegen disebabkan oleh suatu kombinasi kepuasan, rintangan pengalihan (switching barrier) pemasok, keluhan jadi dapat dirumuskan bahwa:

\section{Loyalitas $=\mathrm{f}($ customer satisfaction, switching barriers, voice $)$}

\section{Loyalitas Konsumen}

Seorang dapat dikatakan sebagai konsumen yang loyal adalah seseorang yang membiasakan diri dalam melakukan sebuah pembelian produk atau jasa yang yang di produksi oleh perusahaan. Dorongan atas perilaku konsumen dalam melakukan pembelian dan konsumsi yang dilakukan secara berulang-ulang dengan membangun sebuah kesetiaan terhadap produk/jasa yang diciptakan oleh perusahaan dalam waktu 
yang lama untuk sebuah proses pembelian yang berulang-ulang tersebut adalah loyalitas konsumen (Peter Olson, 1993). Kebiasaan tersebut dapat dibangun melalui pembelian berulang-ulang dalam jangka waktu tertentu, apabila dalam jangka waktu tertentu tidak melakukan pembelian ulang maka orang tersebut tidak dapat dikatakan sebagai Konsumen tetapi sebagai seorang pembeli atau konsumen.

Pendapat tersebut menunjukan bahwa ada cakupan yang lebih luas untuk sebuah nilai dari perilaku konsumen yang loyal. Dalam beberapa pendapat lain mengatakan bahwa konsumen yang setia dan loyal adalah konsumen yang mampu menunjukkan sebuah perilaku dalam melakukan pembelian yang teratur dan terjadi dalam periode yang beruntun untuk jangka waktu yang telah ditentukan, terutama untuk pembelian yang lebih dari dia kali waktu dalam selang waktu yang berbeda.

Upaya yang diciptakan tersebut akan dilakukan dalam mempangaruhi jumlah dari sikap konsumen itu sendiri, dengan beberapa konsep loyalitas konsumen dikaitkan dengan pola perilaku konsumen atas diri mereka sendiri.

Pertama, loyalitas atas perilaku konsumen diukur dari beberapa permintaan untuk pemasangan iklan dalam Website Enterprise dalam jangka waktu tertentu. Konsumen yang rata-rata dalam pemasangannya yang lebih tinggi dapat dikatakan bahwa konsumen lebih loyal dari konsumen yang pemasangan iklannya lebih rendah.

Kedua, loyalitas berkembang terhadap perilaku dan model pembelian atas layanan yang diberikan untuk hal yang dikeluarkan oleh perusahaan untuk tidak beralih dan bergnati seklain menjadi konsumen Media website lain misalnya Rama Enterpise, Tulungagung news dll.,

Ketiga Loyalitas tersebut adalah konsep atas beberapa konsumen untuk memberikan rekomendasi pemasangan iklan kepada orang lain di website tersebut. Konsumen akan menciptakan tingkat nilai yang loyal terhadap memberikan rekomendasi terhadap orang lain untuk memasang iklan di Gadjah Mada Enterprise.

\section{Hubungan Kepuasan Konsumen Terhadap Loyalitas Konsumen}

Dari sisilain konsumen meningkatkan nilai kesetiaan terhadap jasa layanan periklanan yang ditawarkan oleh website GM Enterprise. Hal ini memungkin bagi semua perusahaan dalam melakukan sebuah persaingan sehingga memunculkan sebuah konsep persaingan yang tinggi, beberapa perusahaan bersaing untuk memaksimalkan 
tingkat kepuasan konsumennya agar barang dan jasa yang mereka konsumsi bisa bermanfaat untuk konsumen. (Thomas Jones and W. Earl Sasser. Jr, 1994) menyatakan bahwa loyalitas Konsumen merupakan suatu variabel endogen yang disebabkan oleh kombinasi dari kepuasan sehingga loyalitas Konsumen merupakan fungsi dari kepuasan.

Dari statemen tersebut menyatakan bahwa hubungan antara kepuasan konsumen dengan loyalitas konsumen adalah positif, hal ini dapat di simpulkan bahwa peningkatan indexs kepuasan konsumen akan meningkatkan tingkat loyalitas atas konsumen. Dalam penelitian ini Indeks loyalitas konsumen berfungsi sebagai $\mathrm{Y}$ sedangkan Indeks kepuasan konsumen berfungsi sebagai X. Jones dan Sasser (Thomas Jones and W. Earl Sasser. Jr, 1994), dan dapat di gambarkan dalam sebuah konsep pengaruh antara kepuasan Konsumen dan loyalitas Konsumen sebagai berikut:

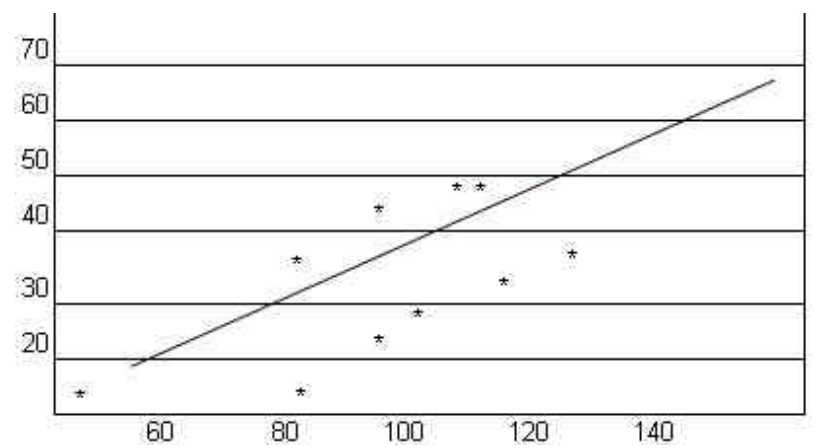

Sumber: Jones \& Sasser, Mark Two Ed.p. 746

\section{Gambar 2. Pengaruh kepuasan Konsumen terhadap loyalitas Konsumen Relation}

\section{between satisfaction \& loyalty}

\section{Keterangan:}

Dalam pasar yang tingkat persaingan cukup tinggi, kepuasan konsumen dan loyalitas konsumen saling berhubungan. Hal ini dapat disebabkan karena dalam kondisi ini banyak badan usaha yang menawarkan produk dan jasa sehingga konsumen mempunyai banyak pilihan produk pengganti dan cost switching sangat rendah, dengan demikian produk atau jasa menjadi tidak begitu berarti bagi konsumen. Hubungan antara kepuasan konsumen dan loyalitas konsumen tersebut diatas digambarkan garis lurus dan searah, yang artinya adalah bila badan usaha meningkatkan kepuasan kepada konsumen maka loyalitas konsumen juga akan meningkat begitu pula sebaliknya bila badan usaha menurunkan kepuasan konsumen maka secara otomatis loyalitas konsumen juga akan menurun. Jadi dalam hal ini kepuasan konsumen merupakan penyebab 
terjadinya loyalitas konsumen sehingga kepuasan konsumen sangat mempengaruhi loyalitas konsumen.

\section{Hipotesis}

Berdasar Tinjauan Pustaka dan teori yang ada, hipotesis berikut dirumuskan: Faktor-faktor kepuasan konsumen (Reliability (keandalan), Response to and remedy of problems (respon dan cara pemecahan masalah), Sales experience (pengalaman karyawan), convenience of acquisition (kemudahan dan kenyamana) berpengaruh terhadap loyalitas Konsumen iklan di Gadjah Mada Enterprise.

\section{METODE PENELITIAN}

Jenis penelitian dengan hipotesis ini adalah survey, yaitu suatu penelitian yang bertujuan untuk mempelajari seberapa besar kepuasan yang dimiliki oleh konsumen terhadap Pemasangan Iklan Website Gadjah Mada Enterprise serta Model pengembangan terhadap Indeks loyalitas Konsumen Gadjah Mada Enterprise.

\section{Identifikasi Variabel}

Variabel-variabel yang digunakan dalam penelitian adalah:

$\mathrm{X} 1$ = Intensifly

$\mathrm{X} 2=$ cross selling

X 3 = convenience of acquisition

\section{Definisi Operasional}

Kepuasan Konsumen (variabel bebas $\mathrm{x}$ )

1. Intensifly (keandalan)

Intensifly merupakan kemampuan perusahaan dalam menghasilkan produk yang sesuai dengan Moto dan slogan yang dimiliki oleh perusahaan. Diantaranya adalah kecepatan dan ketepatan Gadjah Mada Enterprise dengan harga ekonomis dalam mengiklankan di Website.

2. Cross selling (Penanganan Konsumen)

Cross selling merupakan hubungan antara konsumen dengan karyawan Gadjah Mada Enterprise khususnya dalam hal melakukan sebuah komunikasi dua arah yang berhubungan dengan proses pemasangan dan penanganan semua kendala berkaitan 
dengan pemasangan Iklan, yang artinya mencakup memberikan konsultasi masukan, saran dan pendapat kepada konsumen dalam melakukan pemesanan Iklan, dalam layanannya.

3. Convenience of acquisition (kemudahan dan kenyamanan)

Convenience of acquisition merupakan kemudahan dan kenyamanan akses yang diberikan oleh perusahaan dalam melakukan pelayanan kepada konsumen yang berkaitan dengan proses publikasi Iklan di Website melalui Gadjah Mada Enterprise.

Loyalitas Konsumen (Variabel terikat Y)

Variabel terikat Y adalah loyalitas Konsumen yang diukur berdasarkan ukuran perilaku

(behavior measures) yaitu:

1. Keinginan untuk memasang Iklan Website di Gadjah Mada Enterprise pada pemasangan berikutnya.

2. Kesediaan untuk merekomendasikannya kepada orang lain agar memasang Iklan di Gadjah Mada Enterprise.

Dalam pengumpulan data primer peneliti menggunakan daftar pertanyaan yang di sebar melalui laman social media dan korespondensi kepada konsumen Iklan Website GM Enterprise. Sedangkan Model dalam pengumpulan data primer yaitu dengan metode survey serta wawancara langung dengan leat surel dan telephone kepada konsumen Gadjah Mada Enterprise.

\section{Populasi, Sampel, dan Teknik pengambilan Sampel}

Populasi dalam penelitian ini adalah semua konsumen yang pernah menggunakan Iklan dalam Website di Gadjah Mada Enterprise. Sampel yang dimasukkan dalam penelitian ini adalah sebanyak 100 responden, dengan mengingat ada jumlah sampel diatas minimal untuk menghindari sampel error. Kemudian kuisioner dilakukan rekapitulasi elektronik, dan dilakukan diseleksi mendalam untuk kemudian data indeks tersebut diolah serta dianalisis. Teknik pengambilan data menggunakan kuisioner yang diberikan kepada responden pengguna Iklan Website Gadjah Mada Enterprise dan kemudian dilakukan komputasi dan beberapa keterangan 
singkat dalam menjelaskan model singkat mengenai kuisioner tersebut.

\section{Teknik Analisis data}

Teknik yang digunakan dalam analisis ini adalah menggunakan program komputer SPSS. Data yang sudah didapatkan dari hasil Questioner elektronik kemudian dikumpulkan berdasarkan hasil penyebaran kuisioner tersebut, dari data yang didapatkan tersebut dilakukan diseleksi mendalam untuk kemudian data indeks tersebut diolah serta dianalisis. Untuk pengujian model hipotesis penelitian peneliti melakukanya dengan model regresi linier berganda.

Analisa regresi linier berganda adalah model yang difungsikan untuk mengetahui pengaruh atas faktor-faktor yang disebutkan dalam indicator penelitian yaitu meliputi kepuasan Konsumen (Intensifly, cross selling, convenience of acquisition) terhadap loyalitas Konsumen.

Rumus dari Regresi Linier Berganda menurut Newbold (1995:483), adalah sebagai berikut :

$\mathrm{Y}=\mathrm{b} 0+\mathrm{b} 1 \mathrm{x} 1+\mathrm{b} 2 \mathrm{x} 2+\mathrm{b} 3 \mathrm{x} 3$

$\mathrm{Y}=$ Variabel terikat (Loyalitas Konsumen)

b0 $=$ Koefisien konstanta

b1, b2, b3, = koefisien regresi

$\mathrm{x} 1$ = Intensifly (Keandalan)

$\mathrm{x} 2$ = cross selling (Penanganan Konsumen)

$\mathrm{x} 3=$ convenience of acquisition (Kemudahan dan Kenyamanan)

\section{TEMUAN DAN ANALISIS}

\section{Deskripsi Data}

Dari perolehan data yang ada di lapangan dapat disajikan sebagai berikut hasil analisis atas faktor-faktor kepuasan konsumen dan pengaruhnya terhadap loyalitas konsumen serta pemasangan iklan pada website pada Gadjah Mada Enterprise di Tulungagung dari 100 kuesioner yang dilakukan didapatkan beberapa responden dengan rentan usia antara 18 sampai 71 tahun. 
Karakteristik Responden Berdasarkan Jenis Kelamin

Tabel 1. Kelompok Responden Berdasarkan Jenis Kelamin

\begin{tabular}{|c|c|c|}
\hline Jenis Kelamin & Jumlah Responden & Dalam persen \\
\hline Pria & 52 & 52,0 \\
\hline Total & 100 & 100.0 \\
\hline
\end{tabular}

Sumber: data primer diolah

Model Karakteristik Responden Berdasarkan Pendidikan

Tabel 2. Kelompok Pendidikan Responden

\begin{tabular}{|c|c|c|}
\hline Pendidikan & Jumlah Responden & Dalam Persen \\
\hline SD & 0 & 0,0 \\
SMP & 1 & 1,0 \\
SMU & 25 & 25,0 \\
Perguruan Tinggi & 74 & 74,0 \\
\hline Total & 100 & 100,0 \\
\hline
\end{tabular}

Sumber: data primer diolah

Model Karakteristik Responden Berdasarkan Pekerjaan

Tabel 3. Kelompok Pekerjaan Responden

\begin{tabular}{|c|c|c|}
\hline Pekerjaan & Jumlah Responden & Dalam Persen \\
\hline Pegawai Negeri & 2 & 2,0 \\
Pegawai Swasta & 27 & 27,0 \\
Wiraswasta & 71 & 71,0 \\
\hline Total & 100 & 100,0 \\
\hline
\end{tabular}

Sumber: data primer diolah

Model Karakteristik Responden Berdasarkan Frekuensi menggunakan jasa Gadjah Mada Enterprise dalam 1 bulan Terakhir

Tabel 4. Deskripsi Karakteristik Responden Berdasarkan Frekuensi Menggunakan

\section{Gadjah Mada Enterprise}

\begin{tabular}{|c|c|c|}
\hline Berapa Kali & Jumlah Responden & Dalam Persen \\
\hline Kurang dari 3 kali & 17 & 17,0 \\
Lebih dari 3 kali & 83 & 83,0 \\
\hline Total & 100 & 100,0 \\
\hline
\end{tabular}

Sumber: data primer diolah 
Dari tabel-tabel diatas dapat diketahui bahwa konsumen iklan pada Gadjah Mada Enterprise mayoritas adalah pria, berpendidikan SMU keatas, pekerja swasta /wiraswasta dan memasang lebih dari tiga kali dalam sebulan. Hal ini sesuai dengan karakteristik responden yang dibutuhkan dalam penelitian.

\section{ANALISIS DATA}

Proses pengolahan data, serta perhitungan analisa datanya adalah dengan menggunakan komputer yang berprogram SPSS 10.00. Model analisis regresi linier berganda dari pengolahan data diatas, yang dipergunakan sebagai variabel bergantung (Y) yaitu loyalitas konsumen, dan sebagai variabel bebas (X) adalah Intensifly (X1), cross selling (X2), dan convenience of acquisition (X3). Hasil analisis regresi linier berganda disajikan dalam tabel 5:

Tabel 5. Hasil Perhitungan Koefisien Regresi Linier Berganda

\begin{tabular}{|c|c|c|c|c|}
\hline \multirow{2}{*}{ Model } & \multicolumn{2}{|c|}{ Koefisien } & \multirow{2}{*}{ t hitung } & \multirow{2}{*}{ Sig. } \\
\hline & B & Std Error & & \\
\hline Konstan & 1,001 & 0,597 & & \\
\hline Reliability & 0,189 & 0,153 & 1,343 & 0,155 \\
\hline Response to and remedy of problems & 0,129 & 0,123 & 1,032 & 0,104 \\
\hline Cross selling & 0,340 & 0,127 & 2,821 & 0,005 \\
\hline Convenience of acquisition & 0,03989 & 0,148 & 0,242 & 0,791 \\
\hline & $\begin{array}{l}\mathrm{R}^{2}=0,253 \\
\mathrm{~F}=2,46 \\
\mathrm{Sig}=0,00\end{array}$ & & & \\
\hline
\end{tabular}

Sumber : Lampiran

Berdasarkan hasil nalisa diatas menunjukan bahwa

1. Untuk dapat mengetahui apakah variabel bebas secara parsial berpengaruh yang signifikan terhadap variabel terikat dilakukan uji t. Koefisien regresi cross selling bertanda positif (0,343), dimana cross selling berpengaruh positif terhadap loyalitas Konsumen.

2. Dalam Tabel 4.5, terdapat nilai t yang dimunculkan pada kolom 4, sedangkan probabilitas signifikansi terisi pada kolom 5, tingkat probabilitas kurang dari 0,005 yang mana mempunyai arti bahwa variabel bebas berpengaruh signifikan terhadap variabel terikat. 
3. Berdasarkan hasil dari koefisien regresi pada kolom ke 2, dapat diketahui bahwa hanya cross selling yang berpengaruh signifikan terhadap loyalitas karena konsumen memiliki nilai koefisien regresinya lebih besar dari probabilitas signifikansi (probabilitas signifikansi kurang dari 0,05).

4. Dua variabel yang lain yaitu Intensifly, dan convenience of acquisition terbukti tidak berpengaruh signifikan terhadap loyalitas konsumen karena nilai koefisien regresi lebih kecil dari probabilitas signifikansi (probabilitas signifikansi lebih tinggi dari $0,05)$.

5. Nilai koefisien determinasi berganda R2 sebesar 0,253 menunjukkan kontribusi relatif variabel Intensifly, cross selling dan convenience of acquisition. Oleh karena itu semakin tinggi nilai koefisien determinasi parsial semakin tinggi kontribusi variabel bebas dalam menjelaskan variabel terikat.

6. Koefisien determinasi (R2) sebesar 0.253 mengindikasikan bahwa $25,3 \%$ variasi yang terdapat pada loyalitas konsumen dapat dijelaskan oleh variabel-variabel bebas yang digunakan dalam penelitian.

Untuk mengetahui variabel bebas secara simultan adapah terdapat pengaruh yang signifikan terhadap variabel terikat maka akan dilakukan uji F. Hasil pengujian dengan uji $\mathrm{F}(2,46)$ menunjukkan nilai probabilitas signifikansi kurang dari 0,05 yang berarti bahwa variabel-variabel bebas secara simultan berpengaruh signifikan terhadap ROA perusahaan.

\section{PEMBAHASAN}

Kesimpulan dari hasil penelitian ini bahwa Intensifly, cross selling, dan convenience of acquisition secara parsial tidak mempengaruhi secara langsung terhadap loyalitas Konsumen, akan tetapi indeks cross selling secara parsial berpengaruh signifikan terhadap indeks loyalitas Konsumen, sehingga perusahaan harus lebih memperhatikan Indeks cross selling dimana Indeks tersebut dapat memberikan pengaruh yang belih besar dalam meningkatkan kemampuan karyawan dalam perusahaan sehingga mampu memberikan pelayanan yang maksimal untuk pendapat dan saran serta dalam memberikan pelayanannya untuk semua keluhan yang disampaikan dari konsumen untuk melakukan pemasangan iklan di website.

Berdasarkan dari nilai koefisien determinasi indeks cross selling menunjukkan 
bahwa indeks cross selling memberikan efek parsial lebih dominan dibandingkan yang lain terhadap perubahan indeks loyalitas konsumen. Kesimpulan yang dapar di peroleh adalah Gadjah Mada Enterprise sebaiknya lebih mengutamakan indeks cross selling karena memberikan kontribusi terbesar terhadap loyalitas konsumen. Hal-hal yang perlu dilakukan sehubungan dengan hal tersebut yaitu memberikan pengarahan kepada karyawan agar dapat melayani konsumen dengan lebih baik lagi. Walaupun demikian bukan berarti reliability, response to and remedy of problems, dan convenience of acquisition diabaikan, akan tetapi sebaiknya pihak perusahaan juga memberikan pelayanan yang cepat, selalu tepat waktu, dan adanya respon dari karyawan apabila terjadi kompalin tentang iklan

\section{KESIMPULAN DAN SARAN}

Berdasar dari hasil penelitian ini hanya cross selling yang mempunyai pengaruh signifikan terhadap loyalitas Konsumen. Sedang ketiga variabel lainnya Intensifly, s, dan convenience of acquisition terbukti tidak berpengaruh. Namun demikian peneliti mengakui keterbatasan baik dari sisi metodologi maupun implikasi hasil penelitian ini. Keterbatasan sample akan mempengaruhi hasil penelitian, oleh karenanya hasil penelitian ini tidak dapat digeneralisir.Berdasarkan hasil analisis dan pembahasan maka saran yang dapat disimpulkan bahwa variabel yang berpengaruh significan adalah cross selling terhadap loyalitas Konsumen, dengan demikian perusahaan sebaiknya meningkatkan kemampuan karyawan yaitu dengan memberikan training, serta memberi pengarahan kepada karyawan agar dapat melayani Konsumen dengan lebih baik lagi.

\section{DAFTAR PUSTAKA}

Christopher. H Lovelock dan Wright, L. . (2005). Manajemen Pemasaran Jasa. Indeks. Jill Griffin. (1995). Customer Loyalty: How to earn it, How to keep it. USA: A Division Of Simon and Schukers Inc.

John C Mowen. (1995). Consumer behavior (Internatio). New Jersey: Prentice Hall, Inc, Englewood Cliffs.

Peter Olson. (1993). Consumer Behavior and Marketing Strategy (Third Edit). Boston: Richard D. Irwan Inc.

Philip Kotler. (1997). Manajemen Pemasaran: Analisis, Perencanaan, Implementasi 
dan pengendalian (Edisi kede). Jakarta: Salemba Empat.

Philip Kotler and Gary Armstrong. (1996). Principles Of Marketing (Seventh Ed). New Jersey: International Editrion, Prentice Hall, Inc., Englewood Cliffs.

Thomas Jones and W. Earl Sasser. Jr. (1994). Marketing (Second Edition). United States of America: Me Grow Hill Inc. 